and an attorney's daughter from Lincolnshire. Even as a child Pugin showed precocious talent - as a 9-year-old he designed a gothic church and at 15 a sideboard for Windsor Castle. He became expert in medieval work and collaborated successfully with Charles Barry on rebuilding the Houses of Parliament after the 1834 fire.

Pugin came to believe that medieval gothic architecture was the true architecture of the Catholic faith. In 1835 he published Contrasts, a book comparing his ideal of medieval gothic culture with that developing in industrial towns. The book was simplistic, immoderately expressed and ignored the influence of the Renaissance on church building but brought Pugin into the public eye and led to many commissions. In The True Principles of Pointed or Christian Architecture he outlined his own requirements for churches. He designed a great part of the Medieval Court at the Great Exhibition of 1851 and was a judge for other exhibits. In spite of his national prominence, his contributions to major projects and the publication of influential books, he was never accepted by the architectural profession.

Pugin married three times, had several painful infatuations and fathered at least eight children. His life was both driven and blighted by recurring episodes of mental illness. His exceptional energy, quickness in the execution of drawings, remarkable creativity, reckless behaviour and episodes of depression suggest he had an affective disorder. He was admitted to Bethlem with delirium shortly before he died in 1852 at 40 years of age. Diagnoses of thyrotoxicosis and syphilis have also been suggested.

This scholarly work, which places Pugin's work as an artist alongside his changing religious beliefs and his medical condition, makes fascinating reading. One can only be astonished by the architect's extraordinary life and grateful to the author for putting it before us so fully.

Richard H. S. Mindham correspondence c/o British Journal of Psychiatry, 17 Belgrave Square, London SW1X 8PT, UK. Email: bjp@rcpsych.ac.uk

doi: 10.1192/bjp.bp. 108.052662

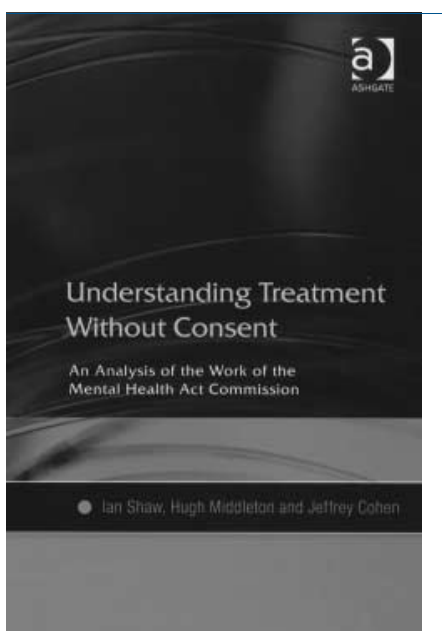

\section{Understanding Treatment} Without Consent: An Analysis of the Work of the Mental Health Act Commission

By lan Shaw, Hugh Middleton

\& Jeffrey Cohen.

Ashgate. 2007. $£ 50.00$ (hb). 138pp.

ISBN 9780754618867

There are eleven biennial reports from the Mental Health Act Commission (MHAC), each longer than the previous one, running to many thousands of pages. Is there any more to say about treatment without consent and the work of the MHAC?

All responsible medical officers and many other psychiatrists whose practice involves treating detained patients, will have come across the MHAC. Some view Commission visits to hospitals as an essential safeguard for patients and a means to improve patient care. Others think that the Commission is an irrelevance whose sole purpose appears, at times, to be complaining that a particular form isn't completed to the Commission's satisfaction. This book describes how the Commission carries out its tasks and the sort of information it collects. But it also goes further. As one reads about the history of the Commission and its predecessor organisations and ponders the type of information collected (both on hospital visits and in relation to requests for second opinion appointed doctors) and, more interestingly, the way it is interpreted in this book, one may gain some insight into how the Commission perceives mental health services and patient detention. The review, by a previous MHAC policy officer, of reform of the Mental Health Act (now rather dated) and of the MHAC itself (through the Health and Social Care Bill), furthers the impression of a Commission with a particular way of seeing the world.

The book also includes a paper on 'treatability' of individuals with psychopathic disorder. Although it doesn't really fit in with the rest of the book, some readers may consider it the most thought-provoking chapter.

However careful one is to think about the impact of detention and use of the Mental Health Act, one of the rewards of working as a Mental Health Act commissioner is gaining a greater understanding of how others, particularly patients, view detention under the Act. This is reflected in the tone of much of what is written. For those who wish to understand better what the MHAC does this book is worth reading.

Anthony Zigmond Newsam Centre, Seacroft Hospital, York Road, Leeds LS14 6WB, UK. Email: anthony.zigmond@leedspft.nhs.uk

doi: 10.1192/bjp.bp.108.052597

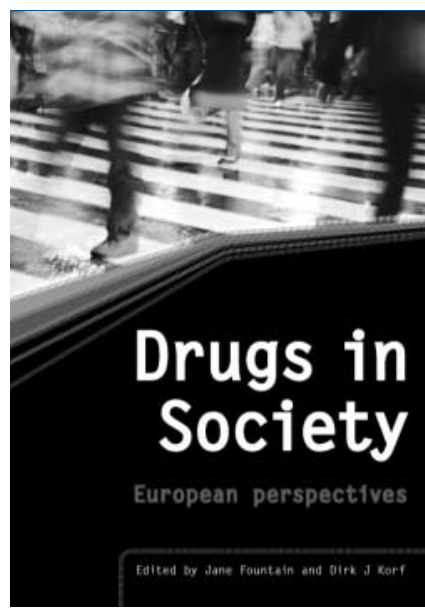

\section{Drugs in Society:} European Perspectives

Edited by Jane Fountain \& Dirk J Korf Radcliffe. 2007. £19.95 (pb). 160pp ISBN 9781846190933

Made up of a collection of papers based on qualitative research in several European countries, this book seeks to illustrate and comment on drug use as a dynamic social behaviour influenced by personal, cultural and political factors. The contributors and editors are all members of the European Society for Social Research on Drugs, a group whose aim is to promote social science approaches to drug research.

The ten papers included tackle a range of subjects and present research in a different way to that which clinicians are accustomed to. Many of the chapters elaborate on the variation in social perceptions and meaning of drug use depending upon the societal 
context, with stigma and the marginalisation of drug users being a common theme throughout. This is expanded further with reference to motivation and meaning behind drug use in particular cultures and the need for culturally sensitive treatment services. Controversial questions are posed regarding the interaction between public opinion, political view and subsequent drug policy and there are interesting discussions regarding the influence of media and clinical research in shaping opinion.

What the book amounts to is largely a collection of opinions and hypotheses where often the evidence that is quoted, and claimed to be systematic, is ill-defined. There is little attempt to undertake the practice, as in traditional scientific papers, of clearly describing methodology and critically discussing models and conclusions. This is the book's major flaw in that it is difficult to consider its assertions critically without the transparency that it claims other clinical research lacks.

Unfortunately, there are obvious factual inaccuracies that lead one to question the credibility of the book, making it even more difficult to know how to regard the conclusions drawn. For example, there is reference to the practice of prescribing oral heroin as a maintenance treatment in the UK, which is clearly not the case, yet the widespread use of oral buprenorphine was omitted.

Beyond the social science field, I question who the target audience for this book is. It attempts to challenge what it views as the black and white medical model of research and policy by putting forward equally monochrome opinions with little supporting evidence. It did, however, succeed in its aim of being provocative and challenging to the reader.

Elizabeth Furlong Birmingham and Solihull Mental Health NHS Trust, Newbridge House, 130 Hobmoor Road, Birmingham B10 9JH, UK. Email: elizabeth.furlong@bsmht.nhs.uk

doi: 10.1192/bjp.bp. 107.04484

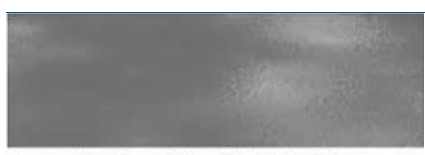

Janet Tieasure, Grimne Smith and Anna Crane

Skills-based Learning

for Caring for a Loved One with an Eating Disorder THE NEW MAUDSLEY METHOD

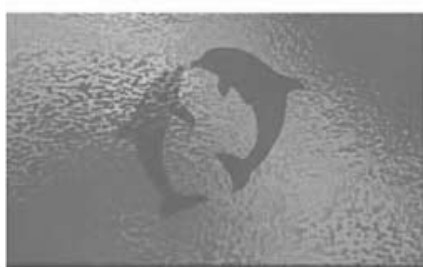

Skills-based Learning for Caring for a Loved One with an Eating Disorder: The New Maudsley Method

By Janet Treasure, Gráinne Smith \& Anna Crane. Routledge. 2007 f12.99 (pb). 228pp. ISBN 9780415431583

The aptly named Treasure and her colleagues have the magpie talent of bringing precious scraps from related fields and fashioning them into accessible and well-researched tools for addressing eating disorders. They borrow motivational enhancement techniques from addictions, skills-training and irreverence from dialectical behaviour therapy, family approaches from child psychotherapy and now the idea of coaching healthy family members in therapeutic techniques, in a manner akin to the Relate manuals, or to Beck's marital self-help Love is Never Enough. ${ }^{1}$
The authors teach a sort of 'unplugged' cognitive therapy that informs compassionate living together. Cognitive-behavioural therapy sophisticates will recognise the book's didactic, respectful, empowering, non-blaming style as Socratic. There are examples of Ellis's 'ABC' analysis, the encouragement of behavioural experiments, cognitive-behavioural therapy's win-win approach and exploration of alternative ways to speak and think together.

Anorexia often makes people engage in cognitive-behavioural therapy in a purely technical way that comes unhitched from the 'bigger picture' unless there is family co-therapy to hold things together. The only robustly evidence-based treatment is 'Maudsely' behavioural family work - this book offers families extra ways to contain their own distress and fine-tune their input to the patient's recovery. I already give Janet Treasure's Breaking Free from Anorexia Nervosa ${ }^{2}$ to all new patients, carers and professionals. I shall now recommend this affordable paperback too - fledgling therapists can also learn much from it.

CD-ROM and web-based versions of this work are being prepared, but don't under-estimate the power of a 'live' group setting with peer support, role-play and laughter - the perfect opportunity for professionals and family to learn together. Material that may appear twee and scripts that seem stilted on the page can be translated and re-modelled by the group into tools for effective caring - and for bonding and catharsis.

Inevitably, people remember this book for its menagerie metaphors. What's your caring style? Rhinoceros, kangaroo or preferably - dolphin? Do you behave like an emotional ostrich, let it all hang out like a jellyfish, or contain your feelings like a helpful St Bernard? As one mother remarked, 'Give me that keg of brandy!'

1 Beck AT. Love is Never Enough: How Couples Can Overcome Misunderstandings, Resolve Conflicts and Solve Relationship Problems through Cognitive Therapy. Harper Collins, 1988.

2 Treasure J. Breaking Free from Anorexia Nervosa: A Survival Guide for Families, Friends and Sufferers. Psychology Press, 1997.

Jane Morris Child and Adolescent Mental Health Services Tipperlinn, Royal Edinburgh Hospital, Edinburgh EH10 5HF, UK. Email: jane.morris@nhslothian.scot.nhs.uk

doi: 10.1192/bjp.bp.108.049379

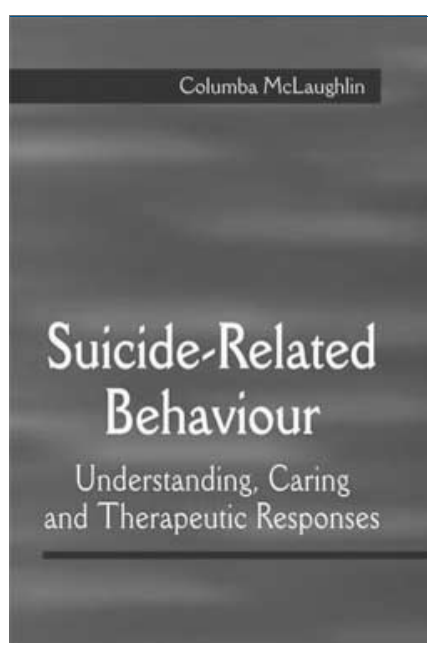

\section{Suicide-Related Behaviour: Understanding, Caring and Therapeutic Responses}

By Columba McLaughlin. John Wiley \& Sons. 2007. f19.99. 230pp (pb). ISBN 9781861565082

This book is aimed at students considering a career in mental healthcare. It consists of two parts.

The early chapters offer case vignettes that introduce conceptual, ethical and attitudinal issues around self-harm, attempted 